\title{
Análise da pertinência do teatro do oprimido para a extensão universitária: perspectivas de jovens residentes em Crato, Ceará
}

\author{
Geovane Gesteira Sales Torres ${ }^{1}$, Caio Ricardo da Silva², Regina Pimentel \\ $\mathrm{Cruz}^{3}$, Maria Isabel de Sousa Bezerra ${ }^{4}$, Diego Coelho do Nascimento ${ }^{5}$
}

Resumo: Esse artigo tem por objetivo avaliar a pertinência da metodologia Teatro do Oprimido para a promoção de ações de extensão universitária em contextos periférico-urbanos por meio da análise dos discursos dos jovens participantes das ações de extensão do Laurbs no bairro Alto da Penha, em Crato - CE. Mediante isso, realizou-se uma pesquisa exploratória, cuja coleta dos dados se deu a partir de um questionário semiestruturado aplicado com jovens residentes na comunidade. O tratamento dos dados qualitativos se deu por meio da técnica análise de conteúdo, já os quantitativos foram tratados com base na estatística descritiva. Os resultados apontam que os participantes enxergam a pertinência do Teatro do Oprimido, avaliando-o positivamente. Conclui-se que metodologias lúdicas como o Teatro do Oprimido são importantes para impactar positivamente a consciência dos jovens sobre o seu território e os seus papéis nele, provocando, assim, o despertar à participação social e à cidadania.

Palavras-chave: Extensão universitária. Teatro do oprimido. Juventudes. Bairros periféricos. Direito à cidade.

Área Temática: Teorias e Metodologias em Extensão.

\section{Pertinence analysis'of the theater of the oppressed for the extension university: perspectives of young people living in Crato, Ceará}

\begin{abstract}
This article aims to evaluate the relevance of the Theater of the Oppressed methodology for the promotion of university extension actions in peripheral-urban contexts through the analysis of the speeches of the young participants of Laurbs' extension actions in the Alto da Penha neighborhood, in Crato - CE. Through this, an exploratory survey was carried out, whose data was collected from a semi-structured questionnaire applied to young residents of the community. The qualitative data were treated by means of the content analysis technique, while the quantitative data were treated based on descriptive statistics. The results show that the participants see the relevance of the Theater of the Oppressed, evaluating it positively. It is concluded that playful methodologies as the Theater of the Oppressed are important to positively impact the awareness of young people about their territory and their roles in it, thus causing the awakening of social participation and citizenship.
\end{abstract}

Keywords: University extension. Theater of the oppressed. Youth. Peripheral neighborhoods. Right to the city.

\footnotetext{
${ }^{1}$ Discente do curso de Administração Pública da Universidade Federal do Cariri (UFCA), foi bolsista de Extensão no Laboratório de Estudos Urbanos, Sustentabilidade e Políticas Públicas (LAURBS) e, atualmente, é bolsista de Iniciação Científica da FUNCAP no LAURBS. E-mail: geovanesalescrato@gmail.com

${ }^{2}$ Discente do curso de Administração Pública da Universidade Federal do Cariri (UFCA), foi bolsista de Extensão no Laboratório de Estudos Urbanos, Sustentabilidade e Políticas Públicas (LAURBS) e, atualmente, é bolsista de Iniciação Científica da FUNCAP no LAURBS. E-mail: caio.ricardo042@gmail.com

Discente do curso de Administração Pública da Universidade Federal do Cariri (UFCA), Bolsista de Extensão no Programa Paidéia Cidade Educadora/Laboratório de Estudos Urbanos, Sustentabilidade e Políticas Públicas (LAURBS). E-mail: reginapimente1932@gmail.com

${ }^{4}$ Bacharel em Administração Pública pela Universidade Federal do Cariri (UFCA) e Pesquisadora no Laboratório de Estudos Urbanos, Sustentabilidade e Políticas Públicas (LAURBS). E-mail: isabelsousabezerra@gmail.com

Licenciado em Geografia pela Universidade Regional do Cariri (URCA), Mestre em Desenvolvimento Regional Sustentável pela Universidade Federal do Ceará (UFC), Doutor em Geografia pela Universidade Federal de Pernambuco (UFPE). Atualmente, Professor Adjunto na Universidade Federal do Cariri (UFCA), coordenador do Laboratório de Estudos Urbanos, Sustentabilidade e Políticas Públicas (LAURBS) e Bolsista de Produtividade BPI da FUNCAP. E-mail: diego.coelho@ufca.edu.br
} 


\section{Análisis de la pertinencia del teatro del oprimido para la extensión universitaria: perspectivas de los residentes jóvenes en Crato, Ceará}

Resumen: Este artículo tiene como objetivo evaluar la pertinencia de la metodología Teatro del Oprimido para la realización de actividades de extensión universitaria en las periferias en el espacio urbano, analizando los discursos de los jóvenes participantes en las acciones de extensión universitaria del Laurbs en el barrio de Alto da Penha, en Crato - CE. A través de esto, se llevó a cabo una investigación exploratória, cuya recopilación de datos se logró mediante un cuestionario semiestructurado aplicado a los jóvenes que viven en el barrio de Alto da Penha. El tratamiento de datos cualitativos se llevó a cabo a través de la técnica de análisis de contenido, y los datos cuantitativos se trataron con la ayuda de la estadística descriptiva. Los resultados indican que los participantes ven la pertinencia del Teatro del Oprimido, dando críticas positivas al respecto. Se concluye que metodologías lúdicas como el Teatro del Oprimido son importantes para impactar positivamente la conciencia de los jóvenes sobre su territorio y sus papeles en él, generando interés en la participación social y la ciudadanía.

Palabras clave: Extensión universitaria. Teatro del oprimido. Juventud. Barrio de la periferia. Derecho a la ciudad.

\section{INTRODUÇÃO}

Trabalhar questões voltadas à urbanidade, à sustentabilidade e às políticas públicas com jovens residentes em comunidades urbanas e periféricas consiste em uma realização demasiadamente complexa devido a fatores materiais, geracionais, territoriais e subjetivos. Perante o exposto, metodologias dinâmicas de integração entre a universidade e a sociedade civil podem propiciar uma aproximação mais harmoniosa com a comunidade, tendo em vista os objetivos de ambos os atores.

O programa de extensão do Laboratório de Estudos Urbanos, Sustentabilidade e Políticas Públicas (Laurbs), ligado à Pró-Reitoria de Extensão (PROEX) da Universidade Federal do Cariri - UFCA, promoveu atividades de extensão universitária para um público-alvo composto por jovens moradores do bairro urbano e periférico Alto da Penha, em Crato-CE, intuindo debater assuntos e realidades locais convergentes aos problemas socioambientais e políticos presentes no território.

Para tanto, o núcleo de extensão em voga atuou no desenvolvimento de momentos de reflexão e discussão com os(as) jovens do bairro Alto da Penha, quando se realizaram atividades inspiradas na modalidade Teatro do Invisível, ramificação cênica do Teatro do Oprimido - TO -, o qual objetiva edificar performances em ambientes do cotidiano, agregando sujeitos que amiúde não consomem produtos culturais como o teatro, além de visar a reprodução de situações de opressão para que os(as) participantes reflitam e reajam a tal. (BOAL, 1991)

O roteiro da intervenção do teatro do invisível no bairro Alto da Penha consistiu na ida à comunidade de representantes de uma empresa do ramo de insumos da construção civil, denominada "CIAMENTO", a qual utilizou da articulação com o poder público municipal e associação de moradores do bairro para se reunir com os(as) jovens da comunidade a fim explicar um projeto a ser edificado no território. O pseudo projeto consistiu na instalação de uma indústria de cimento, bem como do seu escritório local e um depósito, em áreas da periferia onde se localizam a sua única escola pública, a sede da associação de moradores e o prédio de um projeto filantrópico da Pastoral do Menor (Igreja Católica). A proposta também previu que os(as) residentes afetados com a obra seriam realocados para um conjunto habitacional localizado em uma área distante do centro da 
cidade. Por fim, o escopo teatral também versou na realização de promessas profissionais aos residentes na localidade.

Ao término das intervenções cênicas realizadas na comunidade aqui referida no segundo semestre do ano de 2019, o programa de extensão do Laurbs buscou analisar a viabilidade da utilização da metodologia Teatro do Oprimido para ações de extensão universitária. Para tal, realizou-se uma pesquisa exploratória cujo objetivo geral foi avaliar a pertinência da metodologia cênica Teatro do Oprimido para a promoção de ações de extensão universitária em contextos periférico-urbanos por meio da análise dos discursos/opiniões dos(as) jovens participantes das ações de extensão do Laurbs no bairro Alto da Penha, em Crato - CE.

Assim sendo, a pesquisa em foco se mostra relevante, considerando-se que o espaço pesquisado, por se tratar de uma periferia urbana, conta com problemáticas socioambientais múltiplas provenientes de questões como o descaso do poder público. A escolha por trabalhar com jovens se deu pelo fato de tal público ser principiante na vida política institucional, no seu sentido mais abrangente e, por isso, um potencial demandante de diálogos sobre assuntos como o sistema democrático de direito, representatividade política, opressões de diversas naturezas, protagonismo juvenil, gestão social etc.

Então, ao perpassar deste artigo se desenvolverão conceitos tocantes ao Teatro do Oprimido e sua perspectiva transformadora; juventudes, suas tematizações problemáticas e aspirações adultocêntricas impositivas; a situação da extensão universitária em realidades periféricas urbanas, e também considerações a respeito do bairro Alto da Penha, Crato - CE.

\section{O Teatro do Oprimido como método de intervenção social}

A metodologia cênica nomeada Teatro do Oprimido busca, a partir da linguagem teatral e das suas encenações, transformar o(a) espectador(a) passivo(a) em protagonista para que este tome as rédeas da atuação artística e, assim, construa um verdadeiro ensaio para vida em sociedade em que o oprimido poderá finalmente se libertar. Algo claramente exposto por Boal (1991):

O que a Poética do Oprimido propõe é a própria ação! O espectador não delega poderes ao personagem para que atue nem para que pense em seu lugar: ao contrário, ele mesmo assume um papel protagônico, transforma a ação dramática inicialmente proposta, ensaia soluções possíveis, debate projetos modificadores: em resumo, o espectador ensaia, preparando-se para a ação real. (p.138-139).

O contexto histórico em que nasce a metodologia teatral em questão, criada pelo dramaturgo brasileiro Augusto Pinto Boal (1931-2009), situou-se no momento de uma conturbada mudança política e social nacional, considerando-se a instauração do regime civil-militar que se deu entre os anos de 1964 e 1985 no país, e mesmo em meio a tempos de incertezas e obscurantismo, as artes, incluindo-se o teatro, resistiram apesar da veemente repressão institucional vigente no Brasil. (INSTITUTO AUGUSTO BOAL, 2020) 
Afirma-se que as encenações teatrais podem se desenvolver em qualquer local e contexto cotidiano, possibilitando integrar-se ao espetáculo sem mesmo se ter ciência de tal participação. Dentre as modalidades de TO, encontra-se o "Teatro Invisível” que “[...] consiste na representação de uma cena em um ambiente que não seja o teatro e diante de pessoas que não sejam espectadores” (BOAL, 1991, p.167). Apesar da ação teatral ser feita em inúmeros espaços, dadas as variadas situações, necessita-se de um roteiro bem estruturado e planejado com foco nas possíveis adversidades e circunstâncias.

Não obstante, transformar o oprimido em meio a uma sociedade opressora, tão somente é mostrá-lo a sua situação em meio à desumanidade da sociedade, e que mudar a sua realidade parte da libertação dos seus próprios anseios, seus sonhos e sua busca por viver a humanidade. (BOAL,1991). Tão logo, a libertação almejada por Boal (1991) transcende aspectos materiais e institucionais, mas abarca aspectos interpsíquicos e intrapsíquicos.

Portanto, o Teatro do Oprimido nasce das experiências de Augusto Boal e, inspirado em inúmeros eventos históricos e movimentos populares latino-americanos, ansiando a busca por uma sociedade liberta social e politicamente, algo constatado na afirmativa de Boal (1991):

Para que se compreenda bem esta Poética do Oprimido deve-se ter sempre presente seu principal objetivo: transformar o povo, 'espectador', ser passivo no fenômeno teatral, em sujeito, em ator, em transformador da ação dramática. (BOAL, 1991, p. 138)

Então, pode-se pensar a arte como algo que ultrapassa o tempo e que se transforma junto com a sociedade, tornando-se o espelho da humanidade através da história. As artes tomam a forma do mundo e o transformam em algo extraordinário, assim como o teatro pode se tornar um mecanismo de libertação. Nesse sentido, a percepção artística do Teatro do Oprimido contrasta à lógica parnasiana tão somente perseguidora do belo (dimensão estética), sem ânsias ao combate às injustiças sociais e busca pelo bem-viver dos povos. Assim:

O teatro, por intermédio de uma prática libertadora, pode proporcionar a oportunidade a adolescentes de várias idades, alunos e alunas de escolas públicas, ou melhor, educandos e educandas, de ampliar sua habilidade de criação. Esse processo criativo e construtivo permite a eles desenvolverem suas potencialidades de vivência e de convivência na sociedade, de modo mais ativo, integrados socialmente de modo mais humanizado, com mais conhecimento, conscientização e autonomia (OLIVEIRA, 2014, p.16).

Nessa ótica observadora do teatro como uma busca pela libertação dos(as) oprimidos(as), o(a) espectador(a) não é somente àquele(a) que aguarda sentado(a), passivo(a), em sua cadeira o desenrolar das cenas que se darão no palco, pois ele(a) se torna parte integrante do espetáculo, moldando os atos teatrais e os sentimentos a serem expressos, atuando na sua própria narrativa. Dessa maneira, rasga-se o véu dicotômico atores versus espectadores e palco versus plateia. O teatro é, então, um palco onde sonhos e anseios são expostos, onde se expõe o sopro da luta diária por liberdade, algo necessário para a mudança social dos subalternizados. (BOAL, 1991). 


\section{A Extensão Universitária em Contextos Urbanos e Periféricos}

A extensão universitária foi o terceiro pilar acadêmico a surgir, fator que implica nos constantes percalços em compreendê-la e implementá-la, algo que não se aplica com tamanha força aos pilares ensino e pesquisa. Todavia, tal dificuldade não advém apenas da sua relativa recente constituição, mas também do fato da extensão universitária se relacionar com questões complexas de teor político-social. (DE PAULA, 2013)

A sua gênese moderna se situa no contexto posterior à Revolução Industrial, quando as mazelas socioeconômicas provenientes do sistema capitalista nascente demarcavam com intensidade as desigualdades sociais e contradições urbanas. Nesse período localizado entre os séculos XIX e XX, o Estado e outros atores começaram a se voltar para demandas proletárias, ínterim em que a universidade também se direciona para questões sociais. Cabe-se destacar que em seus primórdios, a extensão universitária assumiu duas tendências, a primeira versava amenizar as contradições capitalistas mais nefastas, ao passo que a segunda se guiava à transferência de tecnologias e conhecimentos científicos à sociedade. (DE PAULA, 2013)

No Brasil, a instituição universitária nasce em 1930, porém, a extensão acadêmica apenas tem a sua previsão legal no ano de 1931 (DE PAULA, 2013). Enquanto expoente nas reflexões sobre a educação e extensão universitária, Freire (2006) e o seu postulado desempenharam e persistem influenciando nas definições e práticas sobre tais questões. Desse modo, Freire (2006), ao contemplar a realidade da extensão universitária no período anterior à redemocratização do Brasil, indica que a mesma se configurava pela transmissão vertical de conhecimentos por parte da academia, algo que a figurava como autoritária em impor os seus saberes e em desconsiderar a diversidade cultural e os conhecimentos populares.

Tão logo, havia uma tendência pela mera emissão dos conhecimentos acadêmicos, não uma construção democrática e plural, algo que terminava por gerar um fluxo de "coisificação", em que havia um sujeito e um objeto. Mediante tal realidade antidialógica, Freire (2006) preconiza um processo de extensão em que todos(as) sejam sujeitos. Questão convergente ao pensamento de Freire (1987) ao indicar que a ação-reflexão é o itinerário ideal para que os sujeitos alcancem a sua emancipação, pois a coisificação das pessoas não lhes permite a fala e o protagonismo, já que há uma pressuposição de passividade e receptação de conteúdos considerando-se que segundo essa lógica os "não acadêmicos" seriam desprovidos de razão e conhecimentos. Ante a isso, Freire (1987) exorta para a importância de os(as) oprimidos(as) galgarem a sua libertação por meio de uma educação de caráter popular que se comprometa com a utopia da redução das desigualdades e injustiças sociais.

Em sinergia à Freire (2006; 1987), De Paula (2013) compreende que à extensão universitária cabe responder às demandas sociais por meio de uma relação de reciprocidade em que haja uma troca de saberes científicos e populares, zelando, pois, por uma dialogia e alteridade enquanto questões elementares à emancipação de sujeitos e territórios subalternizados. Confluindo, ainda, ao advogado por Serrano (2013), quando esta aponta 
que a extensão universitária deve ser vislumbrada e edificada como uma prática que encontra na sociedade uma possibilidade de práxis do conhecimento acadêmico. Caminho que gerará uma troca de saberes capaz de produzir conhecimentos adequados às realidades nacional e regionais, além de confluentes aos princípios democráticos. (SERRANO, 2013)

Nesse esteio, interroga-se: qual o papel da extensão universitária frente às antinomias que perpassam os contextos urbanos dos países capitalistas periféricos? Conforme Maricato (2011), a produção do espaço urbano no Sul global se marca pelas vulnerabilidades socioeconômicas por parte dos(as) trabalhadores(as), fator que contribui para a ocupação de áreas inadequadas para habitação e autoconstruções que concebem o que Maricato (2015) denomina como cidades ilegais, referindo-se a áreas urbanas periféricas com infraestrutura deficitária e, amiúde, levadas ao limbo das preocupações públicas.

Maricato (2011) exclama que além de questões históricas (tais como a concentração de terras rurais e a escravidão), as contradições e desigualdades no espaço urbano se justificam pela atuação intensamente comprometida da especulação imobiliária e fundiária. Questão que vai ao encontro do apontado por Corrêa (1989), quando este afirma que o espaço urbano é um cenário no qual se desenvolvem conflitos sociais atuantes na reprodução e fragmentação das tendências postas às distintas classes sociais no que toca à cidadania e ao direito à cidade. Então, concordando com Maricato (2011), Corrêa (1989) destaca os promotores imobiliários e proprietários fundiários como agentes atuantes na produção das cidades capitalistas. Corrêa (1989), ainda, salienta que o Estado não age isento de interesses nas suas ações de ordenação do espaço urbano, já que tende a privilegiar os interesses das elites e grupos economicamente influentes à revelia das parcelas sociais subalternizadas.

Todavia, Corrêa (1989) pressupõe que grupos excluídos existem e resistem nas cidades através dos fluxos de modelação do espaço urbano de forma independente, algo que se concretiza em autoconstruções em localidades periféricas. Além dessa resistência fundada na construção física dos espaços periféricos, Chueca (2018) aponta que no Brasil o direito à cidade nasce na década de 1980 como uma relevante articulação política que uniu variados atores da sociedade civil, contribuindo, dessa maneira, para a construção de muitas e distintas apropriações do espaço urbano. Nesse sentido, Chueca (2018) salienta que elementos como a arte urbana periférica contribuem para a produção de uma cidadania insurgente.

Assim, nota-se uma límpida imbricação entre a busca pelo direito à cidade por grupos socialmente excluídos e a proposta equânime repousante na concepção de extensão universitária, tal como proposta por Freire (2006; 1987), De Paula (2013) e Serrano (2013), julgando-se que conforme esses autores cabe à universidade se posicionar contra as injustiças sociais e, assim, concretizar práticas dialógicas de construção de conhecimentos e ações socialmente comprometidas com a defesa dos direitos humanos e ambientais. Contribuindo, de tal maneira, para desnudar e amenizar as contradições que tanto assolam os contextos urbanos latino-americanos e brasileiros. 


\section{O Bairro Alto da Penha, em Crato - CE}

Situado na cidade de Crato, interior e Sul do estado do Ceará, o bairro urbano-periférico Alto da Penha é um dos mais antigos do município, tendo a sua ocupação territorial iniciada com a chegada de núcleos familiares advindos de diversas cidades do Cariri Cearense. As primeiras residências do local eram construídas com barro, madeira e palhas, algo que reflete as condições socioeconômicas dos(as) ocupantes do espaço desde a sua gênese. Por volta de 1970, o poder público municipal comprou alguns terrenos na área, os quais posteriormente foram loteados e vendidos a valores acessíveis. Além disso, por muitos anos o bairro conviveu com doenças e outros malefícios ocasionados pela presença de um lixão localizado próximo à comunidade, contudo, em meados de 1996 os(as) moradores(as) se organizaram politicamente em prol da retirada do lixão da localidade, assim, após repressões policiais e manifestações, a prefeitura do município se comprometeu com o deslocamento do lixão para outra área. (PRIMO, 2018)

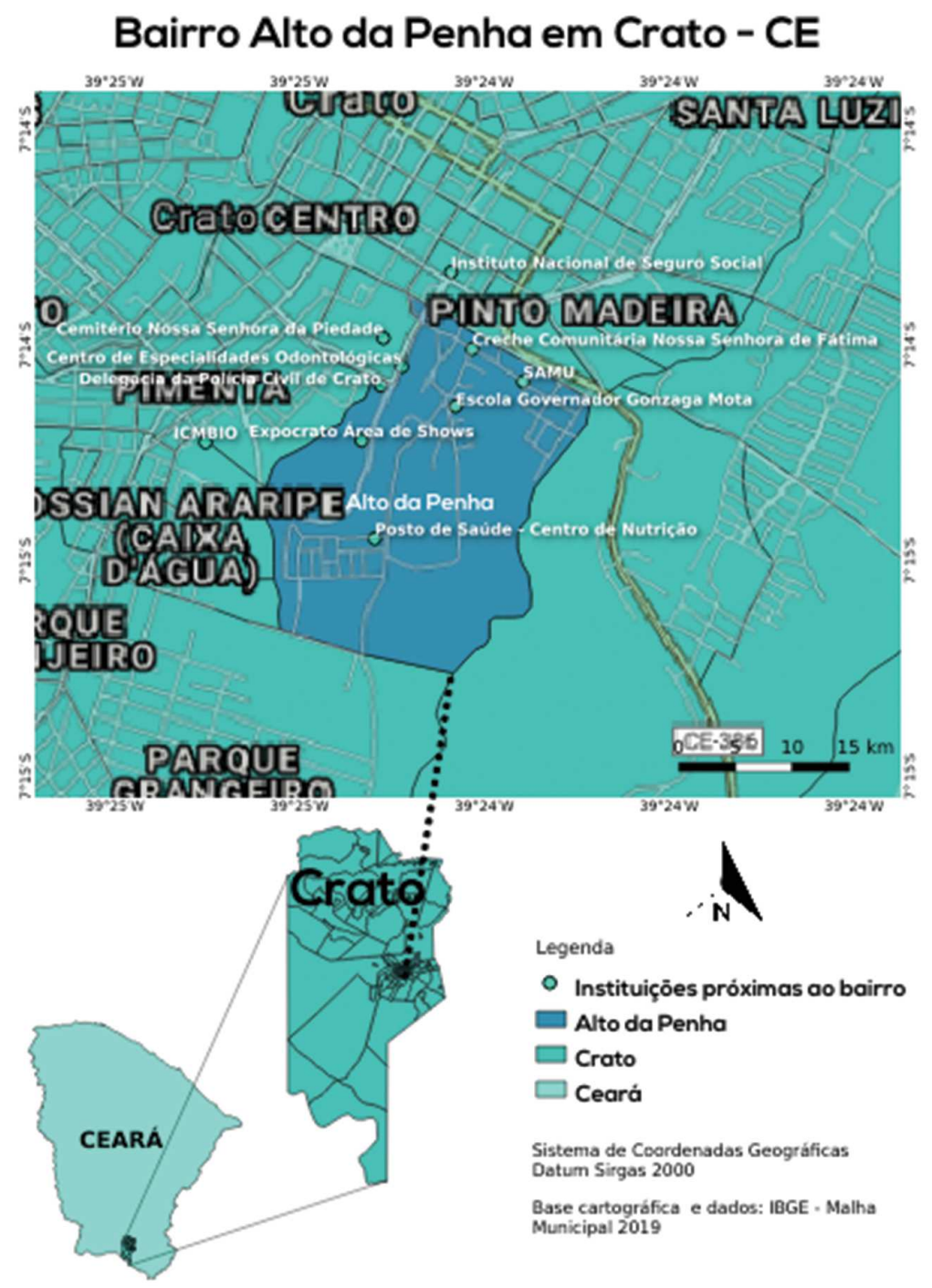

Figura 01: Mapa do bairro Alto da Penha, em Crato - CE.

Fonte: Produzido pelos autores com base nos dados do IBGE através do software livre QGIS. 
Bem como exposto na figura 01, o bairro Alto da Penha se localiza em uma área municipal privilegiada pela presença de equipamentos públicos e por se situar ao lado do Parque de Exposições Pedro Felício Cavalcante, local de realização da Exposição Centro Nordestina de Animais e Produtos Derivados de Crato - CE, maior evento agropecuário das macrorregiões Norte e Nordeste. Todavia, o bairro apresenta deficiências infraestruturais e institucionais basilares, questões notórias ao se contemplar a escassez de saneamento básico e moradias adequadas, além da frágil assistência social, em saúde e segurança pública. Outrossim, considerável parcela dos aglomerados urbanos do bairro se encontra às margens do Cemitério Público Municipal, algo que evidencia a precária qualidade de vida desses sujeitos, amiúde expostos a insalubridades e periculosidades.

Conforme os dados do IBGE (2010), 24,45\% da população do bairro Alto da Penha, em 2010, autodeclarava-se branca, enquanto $12,39 \%$ se autoafirmava preta, 1,37\% amarela, 61,43\% parda e 0,36\% indígena. Nesse sentido, nota-se que os valores de pretos e pardos se sobrepõem às médias nacionais que em 2010 eram, respectivamente, de 7,83\% e 42,98\%. Em relação ao grau de alfabetização, no ano em questão, $82,68 \%$ dos(as) moradores(as) se encontravam alfabetizados(as), porém, tal média se encontrava inferior à nacional, que equivalia a 89,08\%. Ademais, no que toca à questão de gênero, 52,80\% dos(as) residentes na comunidade eram mulheres. Em relação ao aspecto etário, 28,36\% da população local era jovem. (IBGE, 2010)

\section{OBJETIVO}

Motivado pelas ações de extensão universitária supracitadas, esse artigo tem como objetivo geral avaliar a pertinência da metodologia cênica Teatro do Oprimido para a promoção de ações de extensão universitária em contextos periférico-urbanos por meio da análise dos discursos/opiniões dos(as) jovens participantes das ações de extensão do Laurbs no bairro Alto da Penha, em Crato - CE.

\section{METODOLOGIA}

A pesquisa em questão é classificada, em relação aos seus fins, como exploratória, considerando-se que a mesma se trata de uma investigação que anseia contribuir para a geração de maior familiaridade sobre objetos até então pouco ou não explorados, contribuindo, pois, para o desenvolvimento de hipóteses e evidência de temáticas emergentes (MARCONI; LAKATOS, 2009). Dentre as possibilidades provenientes de tal tipificação científica, encontram-se os estudos de caso, os quais consistem em investigações de unidades de forma aprofundada com ênfase em variados aspectos que podem ser tratados com base em naturezas qualitativas e quantitativas. (PRODANOV; DE FREITAS, 2013)

Nesse viés, a investigação em voga se configura como um estudo de caso por se voltar à análise das representações sociais de jovens sobre as suas participações nas atividades do Laboratório de Estudos Urbanos, Sustentabilidade e Políticas Públicas (Laurbs) no bairro Alto da Penha, em Crato - CE. Assim, adota-se como meio da investigação uma pesquisa com survey ex-post-facto, pois a mesma se realizou ao término da situação 
investigada. A pesquisa com survey consiste na coleta direta de dados proferidos por sujeitos cujo comportamento e pensamento se almejam conhecer e estudar, para tanto, frequentemente se empregam questionários pré-definidos. A pesquisa survey se caracteriza pelas seguintes etapas: 1) Definição de objetivos; 2) Delimitação dos conceitos e variáveis empregadas no instrumental; 3) Elaboração do questionário; 4) Realização de pré-teste (facultativo); 5) Delimitação da amostra da pesquisa; 6) Coleta dos dados; 7) Análise e discussão dos dados; 8) Apresentação das informações. (PRODANOV; DE FREITAS, 2013)

O instrumental de coleta de dados foi composto por uma descrição da pesquisa; oito questões objetivas (idade, identidade de gênero, orientação sexual, cor/raça, rendimento familiar, consideração sobre o grau numérico de importância da atividade realiza, consideração sobre o grau numérico da possibilidade de replicação da atividade em outra comunidade, consideração sobre o tipo de impacto causado pela ação); e quatro questões discursivas (opinião sobre a atividade realizada, descrição dos sentimentos durante a ação, perspectiva sobre o bairro onde vive, compreensão relativa à atuação dos poderes executivo e legislativo municipais na comunidade).

O questionário contou com a colaboração de 11(onze) dos(as) participantes da atividade, ou seja, o valor integral dos(as) jovens envolvidos. O tratamento dos materiais seguiu distintas naturezas. As questões objetivas foram analisadas à luz de métodos estatísticos descritivos. Nesse direcionamento, as variáveis estatísticas qualitativas dos tipos nominais e ordinais foram tratadas mediante o cálculo frequencial absoluto, relativo e percentual. O primeiro condiz ao valor de ocorrência das classes em observação (MORETTIN, 2010), já os demais se alcançam pelo emprego das fórmulas descritas no quadro 01:

Quadro 01: Fórmulas das frequências relativa e percentual.

\begin{tabular}{|c|c|}
\hline \multicolumn{2}{|c|}{ Fórmulas Estatísticas } \\
\hline Frequência Relativa & Frequência Percentual \\
$f r=f / \sum f$ & $f \%=100 f r$ \\
\hline
\end{tabular}

Fonte: Elaborado pelos autores com base em Morettin (2010).

Em relação às questões discursivas, as mesmas foram analisadas com base no método análise de conteúdo. Este é uma metodologia interpretativa cuja principal observação se volta ao conteúdo do discurso investigado. Assim, tal método corresponde à adoção de técnicas linguísticas sistemáticas e descritivas dos textos para a realização da análise dos processos comunicacionais. Buscando, dessa maneira, a identificação de conhecimentos relacionados à produção/recepção das comunicações. (BARDIN, 2002)

Não obstante, Bardin (2002) propõe três etapas ideais para a análise do conteúdo, as quais são: 1) préanálise; 2) exploração do material; 3) tratamento dos resultados, inferência e interpretação. A pré-análise consiste na organização dos dados, ou seja, trata-se de um fluxo preliminar. A exploração do material corresponde à concretização e gestão dos pressupostos definidos na pré-análise. Já o tratamento dos resultados, sua inferência e interpretação, constituem-se na observação dos dados aferidos para, enfim, edificar a interpretação do conteúdo textual. 


\section{RESULTADOS E DISCUSSÕES}

Na presente seção se apresentarão os dados diretos obtidos mediante a aplicação da pesquisa com survey, detalhada na seção metodologia. Ademais, os dados ora referidos serão discutidos à luz de teorias críticas pedagógicas, urbanas e sociais relacionadas às juventudes.

\section{O perfil dos(as) interlocutores(as)}

Os(as) interlocutores(as) são integralmente jovens, sendo a sua maioria composta por pessoas com 22 anos de idade (22,27\%), seguidas de sujeitos com 17 (18,18\%) e 18 anos (18,18\%). Já as faixas etárias 15, 19, 20 e 21 anos apresentam o percentual de 9,09\%. No que se refere à identidade de gênero dos sujeitos, nota-se uma pluralidade em que as mulheres cisgêneras ocupam o valor majoritário (45\%), sendo sub sequenciadas por mulheres transexuais (36\%) e, em sobreposição, homens cisgêneros (19\%). Como se percebe, não houve participação de travestis, homens transexuais, bem como de sujeitos com outras identificações de gênero. Porém, identidades dissidentes se encontram bem representadas na presente pesquisa, algo salutar ao se considerar que tais identidades amiúde são alvo de abjeções que terminam por levar as pessoas que as performam a lugares opacos e sem possibilidade de terem as suas vozes ouvidas. (BENTO, 2017)

No tocante às orientações sexuais dos(as) participantes da pesquisa, 63,63\% são heterossexuais, ao passo que as sexualidades homossexuais e bissexuais apresentam o valor 18,18\%. Ademais, tais atores são majoritariamente negros(as) - 54,54\% -, a presença de brancos e pardos apresentam o percentual de 18,18\%, já a participação de amarelos(as) corresponde a 9,09\%.

Em relação aos rendimentos familiares totais, auferiu-se que todos os núcleos familiares dos(as) participantes recebem valores iguais e/ou inferiores a um salário-mínimo. Nesse sentido, 72,72\% dos(as) jovens possuem renda familiar maior que meio e inferior a um salário-mínimo. Em menor número - 18,18\% - se encontram rendas domésticas abaixo de meio salário-mínimo, além de se constarem 9,09\% sem rendimentos familiares.

\section{Opiniões e perspectivas dos(as) participantes}

Ao descreverem os seus sentimentos durante a dinâmica do teatro do invisível, exposta na figura 02 , os(as) jovens participantes apresentaram distintas perspectivas. Cinco desses sujeitos exclamaram incômodos quanto à atividade, algo que se deu, consoante os interlocutores, devido às suas discordâncias quanto ao pseudo projeto a ser implantado na comunidade (elemento motriz da encenação do teatro do invisível). Tais materiais verbais seguem transcritos abaixo:

Respondente 1: "Minha vontade foi de bater naquele [termo homofóbico]"

Respondente 2: "Deu vontade de esculhambar com aqueles [termo degradante] que chegaram se achando" 
Respondente 3: "Quanto mais aquele [termo homofóbico] falava, mais me dava vontade de dar um tiro na cara dele"

Respondente 4: "Senti um ódio da Hinode né minha filha!"

Respondente 5: "Rapaz aquela [termo racista e misógino] falando de nós e de nossas coisas dizendo que ia acabar com tudo ia dar uma putaria grande se fosse verdade." (Sic) (Excertos dos questionários respondidos pelos(as) jovens participantes das atividades).

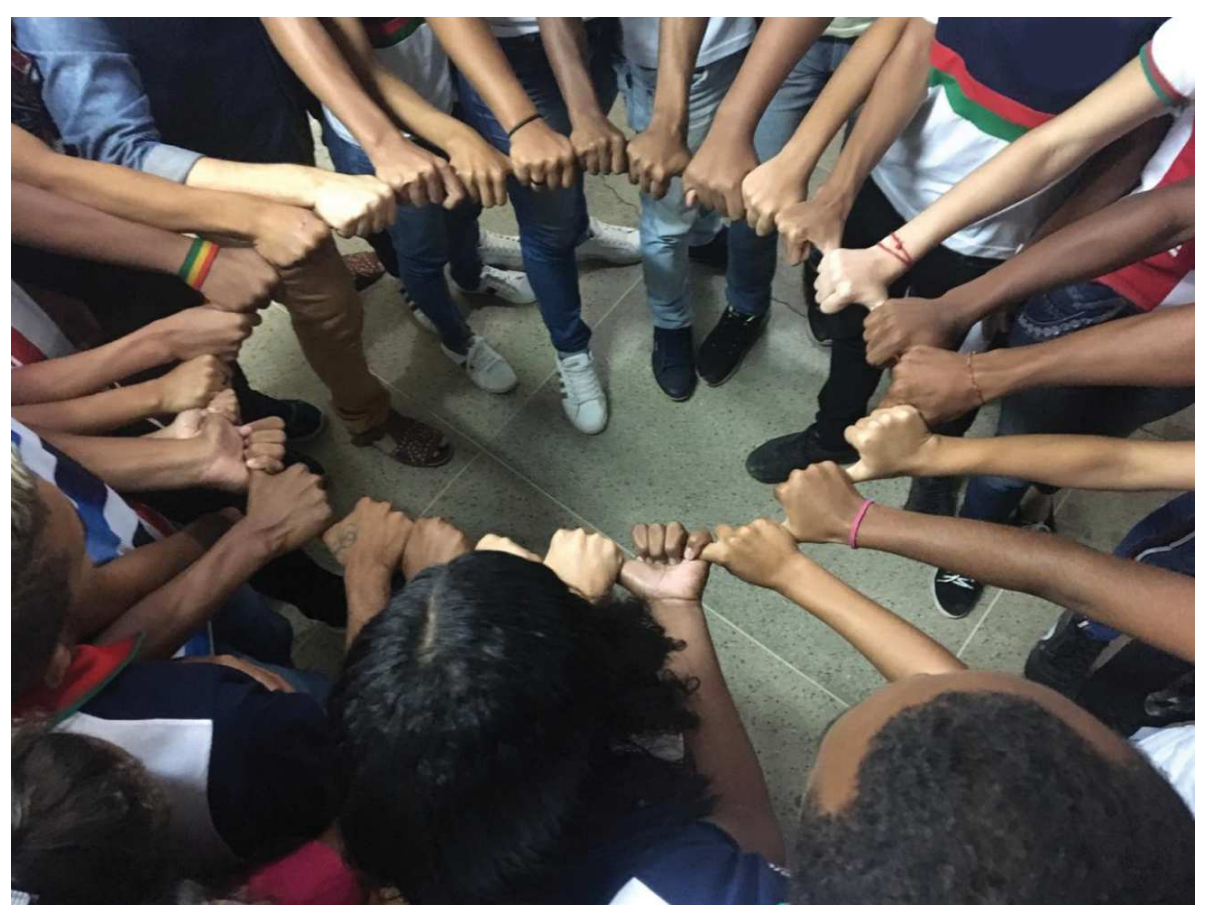

Figura 02: Realização de metodologia integrativa durante a dinâmica do Teatro do Invisível.

Fonte: Arquivo do Laboratório de Estudos Urbanos, Sustentabilidade e Políticas Públicas.

Nesse hiato, utilizaram-se representações sociais que porventura demonstram o sentimento desses jovens em agredir física e verbalmente os(as) representantes da empresa fictícia representados por atores/atrizes protagonistas da dinâmica, fato que se denota nos usos do substantivo "vontade" seguidos de verbos demonstrantes de ações violentas. Contudo, além dessa interpretação, tais expressões podem ser vislumbradas como hipérboles que objetivam enfatizar os sentimentos dos sujeitos contrários ao pseudo projeto empresarial. Assim, empregaramse quatro adjetivos em sentido pejorativo (racistas, homofóbicos e misóginos) para se referirem aos(às) atores/ atrizes que interpretaram os membros da corporação que, conforme o roteiro da intervenção cênica, implantaria uma sede da sua empresa no bairro.

Em ambas possibilidades, o emprego de expressões homofóbicas, misóginas e racistas possibilitam refletir sobre as tensões simbólicas, físicas e institucionais que permeiam os territórios urbanos. Chueca (2018) afirma que além de aspectos materiais, questões de teor subjetivo, tais como a raça, gênero e sexualidade, influenciam a economia política urbana. Assim, em um contexto brasileiro historicamente marcado pelo racismo, heterossexualidade compulsória e binariedade de gênero, os corpos tornados abjetos pelos discursos patriarcais, racistas e LGBTfóbicos são frequentemente alvos de distintas formas de violência, mesmo no seio de grupos socialmente marginalizados (FIGUEIREDO, 2015). Algo notório ao se observar o uso de tal linguagem violenta 
por um grupo de jovens residentes em uma área periférica e composto por variados sujeitos com sexualidades, raças e identidades de gêneros dissidentes. Artefato previsto por Boal (2009), ao elencar que: "É pela posse da Palavra, da Imagem e do Som que os opressores oprimem, antes que o façam pelo dinheiro e pelas armas." (p.40).

Ainda no tocante às perspectivas dos sujeitos em relação à atividade teatral, notam-se visões que demonstram os sentimentos dos(as) interlocutores(as) de que as ações a serem impetradas pelo projeto corporativo desvalorizavam as suas existências. De modo isolado, uma participante exclamou que a ação a possibilitou perceber determinados aspectos da comunidade, algo que apenas foi possível em uma ocasião de risco ao território. Isso se vislumbra nos discursos a seguir:

\footnotetext{
Respondente 6: "Nunca ninguém falou mal da gente assim na cara da gente" Respondente 7: "Além de tudo, senti como se a gente não fosse nada, nem pudesse fazer nada" Respondente 8: "Oxe! Pensei que fosse verdade, ele falando das coisas daqui como se não fosse nada"

Respondente 10: "Comecei a ver que a gente tinha coisas que nem ligava e que por isso vinha aquele povo pra acabar com tudo"(sic) (Excerto dos questionários respondidos pelos(as) jovens participantes das atividades).
}

Observa-se que três dos sujeitos empregam a locução pronominal "a gente", tão logo, nota-se uma possível consciência coletiva no sentido de demonstrarem inconformismo com a alternativa teatralmente construída. Salienta-se que dois(duas) interlocutores(as) utilizaram o vocábulo "nada" para a construção dos seus relatos, sendo que em dois momentos distintos a expressão se refere à desvalorização da comunidade e seus moradores. Nesse esteio, o fragmento "pra acabar com tudo" reforça esse sentido da palavra “nada". Um terceiro uso da expressão exprime o sentimento de impotência ante à ação empresarial teatralmente exposta.

As reações e sentimentos dos(as) jovens participantes das oficinas de Teatro do Oprimido, externados nos repertórios discursivos supramencionados, evidenciam a eficiência da metodologia no seu propósito magno, considerando-se que a ação intuiu simular circunstâncias de opressão para que os(as) interlocutores(as) reagissem a tal situação de modo não submisso. Este é, segundo Boal (2009), o espírito da estética do oprimido, a qual anseia o combate à subserviência e passividade perante conjunturas opressivas, algo que busca "[...] ajudar os oprimidos a descobrir a Arte descobrindo a sua arte; nela, descobrindo-se a si mesmos; a descobrir o mundo, descobrindo o seu mundo; nele, se descobrindo. (BOAL, 2009, p.170).

Nesse direcionamento, a empatia gerada pelo teatro do invisível, modalidade do TO, se constrói porque “[...] pode ser benéfica quando o personagem com o qual nos deixamos empatizar, tanto no teatro como na vida cotidiana, produz ideias e emoções que ajudam o nosso desenvolvimento intelectual e emotivo." (BOAL, 2009, p. 88). Isso não se alcança com intensidade na alternativa teatral tradicional, marcadamente segregada pela dicotomia atores e espectadores. Assim, a metodologia cênica adotada pelo programa de extensão do Laurbs se 
fundou na ascensão dos "espectadores" à categoria de protagonistas do processo teatral, pois, assim é possível intensificar o sentimento de empatia e contribuir para as reflexões dos sujeitos quanto às relações de opressão em que se inserem e as possibilidades de combate às mesmas.

A relevância da metodologia cênica em questão se evidencia ao se contemplar o fato de que $100 \%$ dos(as) jovens julgaram positivo o impacto da ação. Em acréscimo, no gráfico 01 se nota que 63,63\% dos(as) participantes julgaram concordar totalmente com a importância da atividade, enquanto 36,36\% discordaram em partes de tal afirmação. Enfim, $100 \%$ dos sujeitos exclamaram concordar totalmente com a afirmativa de que a oficina do Teatro do Oprimido pode ser realizada em outras comunidades.

Gráfico 01: Importância da atividade segundo os(as) participantes.

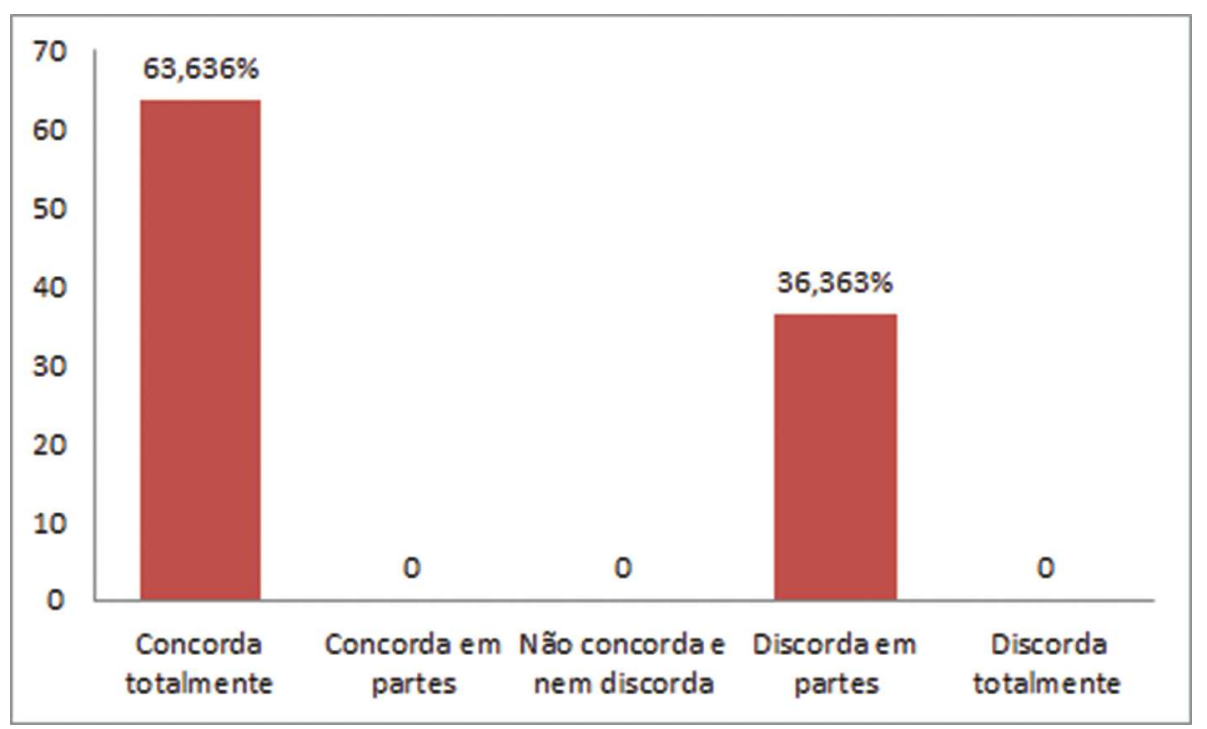

Fonte: Produzido pelos(as) autores(as) com dados da pesquisa.

Como explica Abramo (1997), a juventude figura como um espelho do seu contexto social, sendo representante dos maiores temores, anseios e crenças da sociedade moderna acerca do seu presente e futuro, todavia, não tão relevante a ponto de ser considerada em decisões políticas pertinentes. Trata-se de uma categoria extremamente excluída dos espaços políticos decisórios, somando-se a esse fato a questão da democracia liberal privilegiar certas classes políticas em detrimento de grupos sociais subalternizados, o que só intensifica o problema exposto (FLORENTINO, 2008). Dessa forma, é de suma importância considerar a identidade de gênero, classe, sexualidade e raça dos jovens participantes desse estudo, transcendendo a mera tematização dos mesmos como míseros veículos de problemas sociais.

De modo concentrado, uma interlocutora demonstrou receio no que se refere à reação dos jovens participantes, pois como já conhecia a metodologia cênica e proposta da atividade de extensão, indicou temer comportamentos ariscos devido à encenação não declarada como tal. Esse elemento se nota no fragmento a seguir: 
Respondente 9: "Por que eu já conhecia a metodologia e fiquei com medo da reação do povo daqui, por não haver segurança lá" (sic) (Excerto dos questionários respondidos pelos(as) jovens participantes das atividades).

Tratando-se da questão relativa às percepções dos(as) jovens sobre o bairro onde moram, nota-se um valor considerável de representações sociais que evidenciam a afeição dos(as) interlocutores(as) em relação ao seu território. Estes elementos podem ser contemplados a seguir:

\author{
Respondente 2: "Gosto, mas não sei dizer por quê", \\ Respondente 4: "Bom" \\ Respondente 6: "Bom demais, só falta dinheiro" \\ Respondente 7: "Aqui é massa" \\ Respondente 10: "De bom só tem as coisas que Bel faz" (sic) (Excerto dos questionários respondidos \\ pelos(as) jovens participantes das atividades).
}

Percebe-se um compartilhamento de adjetivos positivos em relação ao bairro, os quais são "bom" e "massa" (sic). Todavia, dois sujeitos apresentam ressalvas em relação aos elogios empreendidos. O primeiro elucida a escassez de recursos pecuniários na comunidade, o que pode indicar problemas relativos ao acesso a bens e serviços fundamentais e/ou à plena empregabilidade. Não obstante, um interlocutor demonstrou a sua visão de que na comunidade apenas são benfazejas as ações feitas por "Bel" (sic). Esta, aqui expressa, é a presidenta da associação de moradores do bairro. Tão logo, tais atividades correspondem às protagonizadas pela entidade ora citada.

Distintamente, parcela expressa dos(as) respondentes apresentaram visões pessimistas no que tange à comunidade. Dessa maneira, sinalizam-se problemas advindos das percepções externas ao bairro, o que faz, em termos dos discursos, com que o local e seus(suas) moradores(as) não sejam priorizados(as) e bem vistos(as) socialmente. Isso se evidencia nos materiais verbais:

Respondente 1: "Lugar esquecido, só se lembram de nós nos tempos das políticas" Respondente 3: "Bom, mas eu gostaria de ir embora porque as pessoas não gostam de nós daqui" (sic) (Excerto dos questionários respondidos pelos(as) jovens participantes das atividades).

Como se observa, o bairro é entendido pelos jovens como um "lugar esquecido", onde seus residentes são estigmatizados socialmente, já que se indica que "não gostam de nós daqui” (sic). O uso do pronome pessoal "nós" em ambos repertórios discursivos reforçam o sentimento coletivo dos interlocutores.

Nesse viés, a estigmatização das periferias urbanas se observa com limpidez nos repertórios discursivos dos(as) interlocutores(as). Em relação à presente problemática, Corrêa (1989) exclama que as zonas periféricas no espaço urbano se marcam por áreas residenciais de baixo status social, pois há uma tendência de concentração de certos grupos sociais em dadas áreas, algo resultante do: “[...] processo de competição impessoal que geraria espaços de dominação dos diferentes grupos sociais" (CORRÊA, 1989, p. 59). Desse modo, a existência de distintas classes sociais culmina na segregação espacial urbana, a qual almeja a manutenção dos privilégios dos 
grupos dominantes e o controle social destes em relação aos subalternizados. Convergindo, assim, à visão de Chueca (2018) de que o crescimento urbano contribui para a segregação espacial de determinados grupos socioeconomicamente desfavorecidos, realidade produtora e disseminadora das periferias desurbanizadas (pois necessitam de fatores constitutivos da vida urbana) e desurbanizantes (porque lhes faltam elementos da vida urbana, já que tais territórios são privados do pleno gozo do espaço público e suas sociabilidades).

Ademais, também se assentam nos discursos esperanças para a resolução dos problemas locais mediante processos de organização comunitária. O que se desnuda nos fragmentos dos discursos:

Respondente 8: "Um lugar complexo, que precisa de muita coisa, mas também da consciência, luta e organização de quem mora aqui"

Respondente 9: "Nós somos pobres, mas somos unidos se mexer com nós"

Respondente 5: "Ta mudando, mas não sei explicar" (sic) (Excerto dos questionários respondidos pelos(as) jovens participantes das atividades).

Novamente, destaca-se a existência de uma possível consciência coletiva percebida nos destaques, algo que em face das adversidades da comunidade, por se tratar de um local "que precisa de muita coisa", demanda alternativas fundadas em articulações políticas locais, tratando-se de uma mudança em curso já perceptível, como enfatiza um respondente.

As articulações comunitárias mencionadas nos discursos em voga são vistas por Santos (2013) como fundadas em valores de autogestão, ênfase em subjetividades, comunitarismo e autonomia nos comportamentos sociais e interesses dos sujeitos. Santos (2013) exclama que as articulações em questão constituem uma sociedade providência, pois através das suas relações de interconhecimento, inter-reconhecimento e cooperação baseadas em laços comunitários, busca-se o mutualismo e resolução de problemas coletivos. Nos arranjos da sociedade providência se assenta o paradigma de desenvolvimento ecossocialista. Este é, para Santos (2013), uma alternativa ao paradigma expansionista dominante, assim, tenciosa a satisfação das demandas humanas essenciais de modo a reduzir as desigualdades sociais; além de equilibrar as formas de propriedade individual, comunitária e estatal.

Ao fornecerem as suas opiniões sobre as formas com que os poderes legislativo e executivo municipais enxergam a comunidade, notam-se pensamentos deveras semelhantes quanto a como a comunidade é tratada pelo poder público. Seis jovens responderam que há uma evidente inação dos poderes citados no que se refere à comunidade, como se constata:

Respondente 1: "Esses ladrões fuleragens não vêem a gente pra ajudar em nada.

Respondente 2: "Pelo que mainha diz que eles deveriam fazer e não fazem, acho que eles não vêem a gente como pessoas que tem direito e que eles devem trabalhar pelo nosso bem"

Respondente 5: “Aquele lote de viado, não vêem nós é de jeito nenhum, mas deixe que as eleições estão chegando e nós vamos dar o troco."

Respondente 6: "Acho que eles não se importam com a gente"

Respondente 8: "Acho que nem ligam"

Respondente 10: "Esses cuzão vê nós pra nada. Só pra pagar o salário deles." (sic) (Excerto dos questionários respondidos pelos(as) jovens participantes das atividades). 
É interessante expor que, bem como em questões anteriores, há um demasiado uso da expressão “a gente" nas respostas, podendo indicar a existência de um compartilhamento de realidades sociais. Os seis discursos acima constantes exclamam as óticas negativas através das quais o poder público vê e age em relação ao bairro Alto da Penha. Assim, são corriqueiras construções linguísticas que evidenciam o descaso dos representantes políticos para com as demandas dos(as) residentes na comunidade, quando se indicam que os políticos não enxergam os sujeitos do território "como pessoas", que "não se importam" e "nem ligam" para o território. Acresce-se que os(as) respondentes se utilizam de termos pejorativos para caracterizar e criticar os representantes do poder público, sendo importante salientar o caráter homofóbico de alguns dos discursos expostos, algo que se fez presente em repertórios anteriormente discutidos.

Santos (2018) afirma que diversos governos democráticos, incluindo-se o Brasil, vivenciam uma intensa crise de representatividade política, pois, a apatia, abulia e acracia política se mostram fortemente presentes nos contextos modernos das democracias representativas. Realidade legitimadora do status quo, pois, o distanciamento dos sujeitos "representados" em relação às decisões políticas contribui para a criação de elites e classes políticas, que por sua vez se utilizam da apatia política dos grupos sociais para a sua promoção e continuidade de privilégios. Algo presente no bairro Alto da Penha, tal como exposto pelos(as) interlocutores(as) quando apontam o descaso dos poderes públicos para com as demandas da comunidade, implicando em uma notória não representatividade das suas necessidades na esfera pública municipal.

O descaso do poder público encontra-se presente em todas as falas dos(as) respondentes, as quais sinalizam a abrangência dessa problemática no tocante ao bairro, porém, acredita-se que na questão juvenil se há um agravante: mesmo não sendo notados(as) pelo poder público, quando o são, encontram-se presos(as) em moldes adultocêntricos (DAYRELL, 2003). Pode-se fazer um paralelo das percepções contemporâneas fixas acerca da juventude com o que foi estudado por Abramo (1997). Afirma este que, na década de 90, devido à ruína de inúmeras instituições de socialização, o aumento do número de jovens na rua tornou-se um problema, tendo em vista a ampliação de ações individualistas e violentas. Assim sendo, os(as) jovens passam a ser visualizados como peças que tolhem ações que tenham potencial benéfico para a sociedade, ou seja, nunca são vistos como sujeitos. Acredita-se que somado a isso, o fato de tratar-se de jovens de comunidades periféricas amplifica e agrava a problemática.

Outrossim, nota-se um pensamento de que a união comunitária do bairro pode impedir democraticamente a perpetuação dessa apatia governamental, o que se percebe com nitidez no repertório discursivo do respondente 5: “[...] deixe que as eleições estão chegando e nós vamos dar o troco.” (sic) (Excerto dos questionários respondidos pelos(as) jovens participantes das atividades).

Além da fragilidade da ação governamental em relação ao território, os(as) jovens do bairro Alto da Penha possuem um notório sentimento de aversão às condutas corruptas por parte de candidatos e ocupantes de funções políticas no seio dos poderes executivo e legislativo, algo que, consoante aos relatos, ganha maior intensidade nos períodos pré-eleitorais: 
Respondente 1: "Só pra roubar e vir pedir voto. Mas deixe eles virem pedir bixiga de voto na minha porta"

Respondente 4: "Local de alienação de voto fácil para compra"

Respondente 7: "Pior que se a gente vota em um não presta, vota em outro não presta. Tem que ficar é sem ninguém nessa porra."

Respondente 9: "Bem, eles nos vêem como uma comunidade pobre e deseperada onde eles conseguem comprar fácil e barato o voto da gente. Pior é que acontece assim mesmo. Eles sempre conseguem. A gente tenta argumentar, conscientiza, mas o povo se vende do mesmo jeito."

Respondente 11: "Acho que não nos enxergam. Estão muito ocupado fazendo ladroagem junto com a peste do prefeito" (sic) (Excerto dos questionários respondidos pelos(as) jovens participantes das atividades).

Em contraste aos discursos acima expostos, um respondente afirma que independente do representante eleito, as problemáticas da comunidade persistem, pois segundo ele "[...] vota em um não presta, vota em outro não presta." (sic) (Excerto dos questionários respondidos pelos(as) jovens participantes das atividades). Grifase que todos(as) os(as) interlocutores(as) relatam uma tendência comportamental relacionada a ida à comunidade de candidatos para a compra de votos durante os períodos pré-eleitorais, quando se destaca a facilidade de compra de votos na localidade, todavia, um interlocutor frisa o esforço para conscientizar a população local em relação à importância de não se votar em pleiteantes de cargos políticos que oferecem barganhas em troca de apoio.

Por fim, duas narrativas destacam que os poderes municipais legislativo e executivo agem racionalutilitariamente em momentos específicos, intuindo o apoio político da comunidade para as suas candidaturas. Elementos que reforçam representações sociais já discutidas anteriormente. Assim, tais iniciativas corruptas são as únicas destacadas pelos interlocutores do bairro Alto da Penha em relação às condutas dos poderes públicos ora destacados, que são criticados pelos respondentes mediante o emprego linguístico de expressões com teor pejorativo:

Respondente 3: "Homem, eles só vêem nós pra pedir voto e fazer nós de besta" Respondente 7: "Esses fudidos vêem nós só pra pedir voto essas mulestas. Aí no tempo das eleições vem tudo viçando, coçando que nem rapariga atrás de voto." (sic) (Excerto dos questionários respondidos pelos(as) jovens participantes das atividades).

Essas percepções sociais obviamente têm consequências deveras trágicas para a nossa democracia, mesmo se tratando de generalizações com bases sólidas no contexto político brasileiro. Argumenta Florentino (2008) que é de praxe encontrar na literatura política a perspectiva de que a juventude de hoje, em contraposição à da década de 60, é alienada e não engajada, não obstante, não é dificultoso visualizá-la em outros meios. Se a concepção da juventude acerca da política se encontra dessa forma, tal fim pode ser contemplado como produto do tratamento da juventude como "problema" e suas dificuldades de se constituir como sujeito de direito na arena política. Dessa forma se terá um cenário próximo do que se vislumbra contemporaneamente, aprofundandose a percepção de "jovem alienado". 
Contudo, os dados aqui expostos acerca da provável consciência coletiva dos(as) interlocutores(as), e da forma com que se articulam enquanto comunidade, é um indício de que, na realidade, os(as) jovens rejeitam veementemente a política formal institucionalizada e as práticas corriqueiramente corruptas que se aproximam do seu espaço em tempos de eleição; mas que se organizam politicamente enquanto população de um território. Como afirma Florentino (2008), deve-se questionar o porquê as juventudes haveriam de se preocupar em demasia com um espaço cristalizado que não as vê, e que, na grande parte das vezes, não causa mudanças efetivas. Cônscio disso, pode-se afirmar que o problema motriz reside nos espaços decisórios e seus atores, e não na essência da juventude. Até mesmo o não-agir pode ser compreendido como posicionamento político, não significando superioridade ao agir e vice-versa.

\section{CONSIDERAÇÕES FINAIS}

Este estudo se deu mediante ações de extensão universitária realizadas no bairro Alto da Penha, avaliadas por meio de um questionário semiestruturado aplicado juntos aos(às) jovens participantes nas ações do Laurbs na localidade. Observou-se a problemática da estigmatização social, juntamente com o perceptível descaso da comunidade por parte do ente municipal, e o sensível teor de descontentamento dos jovens a partir da aplicação da metodologia Teatro do Oprimido. Possibilitando, assim, entender a dinâmica social do bairro e, ademais, observar como os(as) jovens encaram as problemáticas do seu território, além de notar a relação entre os(as) representantes(as) políticos(as) e os(as) moradores(as).

Com relação ao território de realização da pesquisa, têm-se predominantemente características de periferia, que segundo Harvey (2005) e Oliveira (2003), são territórios considerados convergentes a "Desenvolvimentos Geográficos Desiguais" - DGD, ou seja, resultantes de um desenvolvimento desigual em várias vertentes.

A percepção sobre o território foi um fator importante neste trabalho, assim, todos(as) os(as) jovens aqui relacionados(as) residem no bairro Alto da Penha desde o nascimento. Sobre a dinâmica desenvolvida (Teatro do Oprimido), os sentimentos de revolta à pseudo intervenção corporativa foram visíveis.

Metodologias lúdicas como o Teatro do Oprimido são importantes para impactar positivamente a consciência dos(as) jovens sobre o seu território e os seus papéis nele, provocando, assim, o despertar à participação social. Os resultados da pesquisa em voga apontam que $100 \%$ dos(as) jovens participantes das ações avaliadas julgaram positivo o impacto das atividades, enquanto 63,63\% as consideraram importantes, e $100 \%$ acreditam que as ações podem ser replicadas em outras comunidades.

É mister frisar que os repertórios discursivos analisados sinalizam o inconformismo dos(as) jovens ante situações de opressão, rejeição às condutas políticas corruptas e pouco interessadas no bem-estar da comunidade, além de esperança em articulações comunitárias para a resolução dos problemas locais. Questões que confirmam a hipótese de que a metodologia cênica Teatro do Oprimido se mostra relevante para a promoção de ações de 
extensão universitária em contextos territoriais periféricos, considerando-se o seu potencial reflexivo gerador de intervenções sociais coletivas.

Possibilitou-se perceber a consciência dos(as) interlocutores(as) sobre as potencialidades e desafios do bairro onde residem para fins de desenvolvimento. Eles talvez não saibam como resolver os problemas ou potencializar as situações positivas, mas, certamente sabem onde estão os problemas e as suas forças. Questões que em tese deveriam ser consideradas pelo poder público municipal, porém, os discursos apontam o inverso.

Percebe-se que quando a juventude se encontra em comunidades urbanas e periféricas, que em ampla maioria são locais pouco observados pelo poder público, reconhecer a possibilidade de mudanças das realidades locais a partir do contato com entes externos ao bairro, contribui para romper com a estigmatização do lugar onde se vive. Nesse sentido, a partir dos dados aqui evidenciados, observou-se que uma venda porventura começou a ser retirada dos olhos dos(as) participantes das ações, algo que possivelmente os(as) auxiliou a conhecerem e enxergarem os seus direitos e o seu papel democrático.

Porém, percebe-se que a quebra da estigmatização não é uma fácil missão, pois há um cenário histórico de abandono e injustiça edificado pelo Estado e outros atores/atrizes, assim, a sua fragmentação é uma luta árdua que apenas será possível pela atuação de uma sociedade que aprendeu a não mais reconhecer o poder público ou entes externos como messias/redentores, mas sim a construir uma história em que os(as) protagonistas sejam o povo e em que o clímax seja o bem-estar coletivo. Dessa forma, as cortinas da justiça social se abrirão para o início de um espetáculo em que não mais hajam oprimidos(as) e opressores(as).

\section{REFERÊNCIAS}

ABRAMO, Heleno Wendel. Considerações sobre a tematização social da juventude no Brasil. Rev. Bras. Educ., São Paulo, n. 5/6, p. 25-36, 1997.

BARDIN, Laurence. Análise de Conteúdo. Lisboa: Edições 70, 2002.

BENTO, Berenice.Transviad@ s: gênero, sexualidade e direitos humanos. Salvador: EdUFBA, 2017.

BOGHOSSIAN, Cynthia Ozon; MINAYO, Maria Cecília de Souza. Revisão sistemática sobre juventude e participação nos últimos 10 anos. Saúde soc., São Paulo, v. 18, n. 3, p. 411-423, 2009.

BOAL, Augusto. Teatro do Oprimido e Outras Poéticas Políticas. 6. ed. Rio de Janeiro: EDITORA CIVILIZAÇÃO BRASILEIRA S.A., 1991.

BOAL, Augusto. A estética do oprimido. Rio de Janeiro: Garamond, 2009.

CHUECA, Eva Maria Garcia. O direito à cidade pode ser emancipatório?: Presenças, ausências e emergências na construção do direito à cidade no Brasil. 2018. Tese (Doutorado em Pós-colonialismos e Cidadania Global). Faculdade de Economia, Universidade de Coimbra, Coimbra, 2018.

CORRÊA, Roberto Lobato. O espaço urbano. São Paulo: Ática, Série Princípios, 1989. 
DE PAULA, João Antônio. A extensão universitária: história, conceito e propostas. Interfaces - Revista de Extensão da UFMG, v. 1, n. 1, p. 5-23, 2013.

DAYRELL, Juarez. O jovem como sujeito social. Rev. Bras. Educ., Rio de Janeiro, n. 24, p. 40-52, 2003.

FIGUEIREDO, Angela. Carta de uma ex-mulata à Judith Butler. Revista Periódicus, v. 1, n. 3, p. 152-169, 2015.

FLORENTINO, Renata. Democracia Liberal: uma novidade já desbotada entre jovens. Opin. Pública, Campinas, v. 14, n. 1, p. 205-235, 2008.

FREIRE, Paulo. Pedagogia da Autonomia: saberes necessários à pratica educativa. 34. ed. São Paulo: Paz e Terra, 2006.

FREIRE, Paulo. Pedagogia do Oprimido. Rio de Janeiro: Editora Paz e Terra, 1987.

HARVEY, David. A produção capitalista do espaço. São Paulo: Anna Blume, 2005.

IBGE - Instituto Brasileiro de Geografia e Estatística. Censo de 2010. Disponível em: <http:// www.censo(2010).ibge.gov.br/>. Acesso em: 14 Ago 2020.

INSTITUTO AUGUSTO BOAL. Vida e Obra de Augusto Boal. [2020]. Disponível em: <http:// augustoboal.com.br/vida-e-obra/>. Acesso em: 29 Mai 2020.

LAKATOS, Eva Maria; MARCONI, Marina de Andrade. Metodologia do trabalho científico: procedimentos básicos, pesquisa bibliográfica, projeto e relatório, publicações e trabalhos científicos. 7. ed. São Paulo: Atlas, 2009.

MAGALDI, Sábato. Um palco brasileiro: o Arena de São Paulo. São Paulo: Brasiliense, 1984.

MARICATO, Erminia. A cidade sustentável. In: Congresso Nacional de Sindicato de Engenheiros, $9^{\circ}$. 2011.

MARICATO, Ermínia. Para entender a crise urbana. CaderNAU, v. 8, n. 1, p. 11-22, 2015.

MORETTIN, Luiz Gonzaga. Estatística básica: probabilidade e inferência. Volume único. Londres: Pearson Prentice Hall, 2010.

MOSTAÇO, Edélcio. Para uma história cultural do teatro. ArtCultura Uberlândia, v.20, n. 36, p.193203, 2018.

OLIVEIRA, Francisco. Crítica à razão dualista: o ornitorrinco. São Paulo: Boitempo, 2003.

OLIVEIRA, Marcia Cristina Polacchini de. Arte em Cena: teatro na escola pública como prática de liberdade. 2014. Tese (Doutorado em Educação, Arte e História) - Universidade Presbiteriana Mackenzie, São Paulo, 2014.

PRIMO, Raimundo Edilglecio Correia. Cultura Sustentável: Protagonismo Comunitário, Desenvolvimento e Sustentabilidade no Alto da Penha em Crato-CE. 2018.Trabalho de Conclusão de Curso (Bacharelado em Administração Pública) - Universidade Federal do Cariri, Juazeiro do Norte, 2018. 
PRODANOV, Cleber Cristiano; DE FREITAS, Ernani Cesar. Metodologia do trabalho científico: métodos e técnicas da pesquisa e do trabalho acadêmico. 2. ed. Novo Hamburgo: Editora Feevale, 2013.

SANTOS, Boaventura de Souza. Pela mão de Alice: o social e o político na pós-modernidade. 14. ed. São Paulo: Cortez, 2013.

SANTOS, Igor. Crise de representatividade e Neopopulismo: uma regressão aos direitos humanos. Revista Eletrônica Direito e Sociedade - REDES, v. 6, n. 1, p. 117-131, 2018.

SERRANO, Rosana Maria Souto Maior. Conceitos de extensão universitária: um diálogo com Paulo Freire. Grupo de Pesquisa em Extensão Popular, v. 13, n. 8, 2013.

Submetido em: 10/02/2021. Aceito em: 16/03/2021 